\title{
UM ARGUMENTO A FAVOR DA NÃO JUSTIFICAÇÃO DAS CRENÇAS BASE
}

\author{
Pedro Henrique Nogueira Pizzutti \\ Graduando em Filosofia - UEL \\ Orientadora: Mirian Donat
}

\section{RESUMO}

E se na base do nosso sistema de crenças não estiver um princípio fundador seguro? Esta é a questão por detrás do presente trabalho, que busca seu desenvolvimento através do pensamento de Wittgenstein na obra Da Certeza. Estamos persuadidos de que o que está na base do nosso sistema de crenças justificadas são crenças não justificadas, ou melhor, um modo de agir não fundamentado. Para arguir em favor de tal ideia fazemos um caminho pelo pensamento de Wittgenstein na obra acima citada, de tal forma que nos deparamos com um conceito chave para a compreensão da tese, é ele: imagem de mundo. A imagem de mundo, grosso modo, é o pano de fundo que nos foi ensinado, portanto herdado da tradição, e que está no horizonte de nosso julgar. A ideia aqui que procuraremos explorar é que simplesmente algumas crenças são firmes para nós e que elas são o eixo de rotação de todo sistema de crenças. De tal forma que tudo gira em torno, a nosso ver, de uma intersubjetividade da nossa imagem de mundo que nos permite dialogar sobre o mundo e mais importante que influencia na maneira como entendemos o próprio mundo.

Palavras chave: Wittgenstein, crenças-não-justificadas, conhecimento, imagem de mundo.

\begin{abstract}
And if in the basis of our belief system isn't a founding insurance principle? This is the question behind the present paper, who searches your development through Wittgenstein's thought at On Certainty. We are convinced that what are at the root of our justified belief system are beliefs that are not justified, or rather, a way of acting not founded. To argue in favor of this idea we made a path by the thought of Wittgenstein in the above cited work, so that we come across a key concept for understanding the thesis, it is: world image. The world image, roughly, is the background of what we were taught, thus inherited from tradition, and that is on the horizon of our judgment. The idea here is try to explore that some beliefs are just firm for us and they are the axis rotation of the whole belief system. Such that, in our view, it is an intersubjectivity of our world image that allows us to talk about the world and most important influences on the way we understand the world itself.
\end{abstract}

Keywords: Wittgenstein, not-justified-beliefs, knowledge, world image. 


\section{SEMINÁRIO DE PESQUISA EM CIÊNCIAS HUMANAS - SEPECH \\ Humanidades, Estado e desafios didático-científicos \\ Londrina, 27 a 29 de julho de 2016}

\section{INTRODUÇÃO}

Se o caminho para a construção de um conhecimento seguro for aquele trilhado pelo Descartes em suas Meditações, estamos perdidos. Há um comentário virtuoso sobre a dúvida metódica cartesiana nas Investigações Acerca do Entendimento Humano de David Hume, “(...) se um ser humano pudesse alcançar a dúvida cartesiana - o que é simplesmente impossível - ficaria completamente incurável, e nenhum raciocínio jamais poderia conduzi-lo a uma situação de segurança e de convicção sobre qualquer tema." (HUME, 1992, pg. 137). Parte-se aqui do ponto de que todos estão de acordo que nossas crenças formam um sistema, metaforicamente substituiremos por edifício nas sentenças a seguir. O que Descartes pretende com a dúvida metódica é encontrar um fundamento não apenas sólido, mas absolutamente verdadeiro, para a construção do edifício posterior não poder ser abalado de forma alguma, e assim as nossas crenças serem justificadas e verdadeiras, diz ele em suas Meditações:

Há já algum tempo eu me apercebi de que, desde meus primeiros anos, recebera muitas falsas opiniões como verdadeiras, e de que aquilo que depois eu fundei em princípios tão mal assegurados não podia ser senão mui duvidoso e incerto; de modo que era necessário tentar seriamente, uma vez em minha vida, desfazer-me de todas as opiniões a que até então dera crédito, e começar tudo novamente desde os fundamentos, se quisesse estabelecer algo de firme e de constante nas ciências. (DESCARTES, 1988, pg. 17)

Sabemos como Descartes segue nas meditações, como encontra o tão famoso na filosofia "duvido, se duvido,penso, se penso, logo existo" que é a certeza fundadora que seria o alicerce não passível de dúvida onde se fundaria todo edifício do conhecimento, e como ele tem de fazer utilizando de todo engenho argumentativo para superar as limitações que ele mesmo havia se imposto com a dúvida metódica. Sabemos que ele não consegue nos devolver a segurança nas crenças mais básicas que a dúvida nos tirou, e ainda bem que a levamos a sério apenas lendo o texto de Descartes e não para a vida, imagine duvidar da realidade do ônibus que outro dia quase acertou uma senhora, que só não o fez porque ela acreditou piamente em seus sentidos e pulou de volta para a calçada. Tese interessante parece a de Hume que mostra que nossas crenças quanto a questões de fato nunca gozaram e nem gozarão do status de certeza, apenas do status de probabilidade; que a justificativa de nossas crenças se funda numa espécie de instinto que nos faz acreditar que aquilo que ocorreu no passado torna a se repetir de maneira semelhante no futuro. Não pretendemos fazer uma analise da tese humeana, mas cabe dizer que não a julgamos incorreta, mas sim apenas incompleta no que tange a desconsiderar fatores culturais e sociais para a formação de nossas crenças, fatores estes que pensamos ser o ponto chave para o presente trabalho, uma vez que para Wittgenstein "Aquilo em que acreditamos depende do que aprendemos. Todos nós acreditamos ser impossível ir à Lua; mas pode haver pessoas que acreditam que isso é possível e que às vezes acontece.” (DC, §286).

Voltando ao Descartes, será que ele realmente colocou tudo em dúvida a ponto de não haver mais nada de certo e seguro? O pensamento que é o cerne argumentativo 


\section{SEMINÁRIO DE PESQUISA EM CIÊNCIAS HUMANAS - SEPECH \\ Humanidades, Estado e desafios didático-científicos \\ Londrina, 27 a 29 de julho de 2016}

deste trabalho afirma que não: para Wittgenstein, a dúvida só faz sentido dentro de um jogo de linguagem, se retirado dele a própria dúvida perderia o sentido e não poderia se

dizer que ela tem significado, em resumo, a dúvida só tem sentido dentro de um sistema e este já pressupõe algumas coisas como certas em sua base. Isso parece ficar mais claro quando, por exemplo, voltamos ao texto de Descartes e nos perguntamos se em algum momento ele duvidou que pensasse em latim ou francês. Ora, se a intenção era colocar tudo em dúvida, como ele poderia acreditar que seu pensamento ainda se passava no idioma que ele julgava se passar? Parece que afinal ele não se desfez de todas as crenças que poderiam o enganar, no limite, podemos dizer que Descartes nunca aplicou a dúvida metódica como diz que o fez, afinal, "Quem quisesse duvidar de tudo, também não chegaria a duvidar. O próprio jogo da dúvida já pressupõe certeza.” (DC, §115).

Portando, a ideia que nos move é simplesmente inverter a tentativa filosófica amplamente adotada, não mais achar um alicerce seguro para se construir o edifício, mas sim o edifício justificar de alguma forma os seus alicerces. Para isto, este trabalho quer apresentar algumas ideias e defendê-las na medida do possível quanto ao pensamento de Ludwig Wittgenstein deixados em cadernos de anotações feitas por ele dentre os anos de 1949-51, compiladas e publicas posteriormente em um livro chamado Da Certeza. Basear-se-á nesta obra para apresentar que quando duvidamos tomamos por certo algumas crenças; que aprendemos e constituímos crenças que não são postas em dúvida e que assim fundam nosso sistema de crenças, mas que elas em si não são justificadas; que determinadas proposições aparentemente empíricas funcionam como normas do nosso julgar; que há uma imagem de mundo a partir da qual lemos o mundo; que o verdadeiro e o falso só são possíveis já dentro de um sistema; e tentaremos por fim, apontar alguns caminhos para os quais poderão levar nossa pesquisa.

\section{UMA CONSTRUÇÃO A PARTIR DO DA CERTEZA}

Para começarmos a discorrer sobre o Da Certeza não podemos deixar de falar de George Edward Moore e seus dois mais conhecidos artigos, a saber, Uma Defesa do Senso Comum e Prova de um Mundo Exterior. Nestes artigos Moore elenca certas proposições que ele diz saber com certeza que são verdadeiras, tais como em Uma Defesa do Senso Comum, "Existe presentemente um corpo humano vivo, que é meu corpo.(...).Desde que nasceu sempre esteve em contato com a superfície da terra ou não longe dela;(...) Mas a terra existiu também por muitos anos antes que meu corpo nascesse;(...)" (MOORE, 1989, pg. 243-244).Já no artigo Prova de um Mundo Exterior Moore pretende demonstrar, como diz o título, a existência do mundo exterior e o argumento grosso modo é: enquanto gesticula suas mãos, Moore diz: eis aqui uma mão, eis aqui outra mão, portanto algum objeto do mundo exterior existe, então existe o mundo exterior. Em resumo, as proposições do Moore são obviedades que todos nós "sabemos". Wittgenstein usa muito o exemplo "Eu sei que isto é uma árvore" e nas notas finais também utiliza muito "Eu sei que me chamo L.W.". É claro que nosso enfoque não são os artigos do Moore, mas como a discussão de Wittgenstein no $D a$ Certeza nasce da conversa que Wittgenstein travou com um amigo nos Estados Unidos sobre estes dois artigos de Moore e as notas fazem referência a todo tempo, não poderíamos de maneira alguma deixar o leitor perdido nesse sentido. Cabe, portanto 


\section{SEMINÁRIO DE PESQUISA EM CIÊNCIAS HUMANAS - SEPECH \\ Humanidades, Estado e desafios didático-científicos \\ Londrina, 27 a 29 de julho de 2016}

perguntar se Moore sabe realmente com certeza aquilo que ele diz saber, por exemplo, ele poderia se defender do tão famoso argumento do sonho do Descartes? Acreditamos que não e em seus artigos ele também não faz questão de apresentar uma possível

defesa aos argumentos céticos, apenas afirma saber com certeza e que todos os outros humanos também sabem com a mesma certeza, aquilo que ele afirma saber.

É no sentido de discutir o papel da certeza nos jogos de linguagem que entram as anotações de Wittgenstein, e a primeira distinção que queremos fazer para a construção da nossa ideia é justamente entre "Eu sei..." e "Eu acredito...". Uma vez que se pode compreender, assim como acreditamos que Moore fez, e como parece que Wittgenstein entende que Moore faz, o "Eu sei..." como uma exteriorização de grau do estado mental de absoluta certeza. Mas vejamos a distinção apresentada no Da Certeza, "Seria correto dizer: "Eu acredito ..." tem uma verdade subjetiva; mas "Eu sei ..." não. Ou ainda: "Eu acredito ..." é uma exteriorização, mas "Eu sei ..." não." (DC, §§ 179-180). Portanto o uso errado que Moore faz da proposição "Eu sei ..." segundo Wittgenstein é entendê-la justamente como uma exteriorização que não é dubitável, no sentido de que se alguém fala "Eu sei que é assim" segue-se necessariamente que "É assim", mas como diz Wittgenstein, “(...). E sempre se esquece da expressão "Eu acreditei que sabia" (DC, $\S 12)$. Portanto queremos apresentar a ideia de que o "saber" pede razões, que sejam reconhecidas por aquele a quem você explicita, e nesse sentido dentro de um sistema de crenças o saber é justificado objetivamente, "Não seria suficiente garantir que sei o que se passa aqui e ali - sem oferecer razões que convençam (uma outra pessoa) que estou em condições de saber." (DC, §438). Mas aqui ainda não foi dito tudo que deveríamos dizer para seguir em frente.

Dissemos acima que não bastaria apenas dizer que sei, mas sim que temos que oferecer razões para tal, de modo que a proposição "Eu sei..." por si só não nos dá garantia alguma, por exemplo, um amigo te diz, "Eu sei que o último ônibus parte da universidade às $23 \mathrm{~h} 40 \mathrm{~min}$ ", mas poderia você leitor perguntar a ele "Como sabe?", e ele ofereceria então razões para tal, "Eu vi o itinerário dos ônibus que partem da universidade, além de todos os dias pegar este mesmo ônibus que estas perguntando a que horas passará." , e assim seu amigo convencer-te-ia que sabe aquilo que diz saber, pois você admitirá que ele está realmente em condições de saber tal coisa. Mas temos de oferecer alguma razão, por exemplo, quando dizemos "Eu sei que me chamo 'fulano de tal"'? Não, todos admitem que saibamos nossos respectivos nomes, e este tipo de certeza, a saber, a que sabemos nosso nome, não é justificada, pois qualquer justificativa para ela seria menos segura que a própria segurança neste saber, de modo que há "certezas" não subjetivas, mas sim objetivas compartilhadas por todos nós em certos "saberes", portando queremos deixar claro que para Wittgenstein "'Saber' e 'segurança' pertencem a categorias diferentes. Não são dois 'estados da mente', como, por exemplo, 'supor' e 'estar seguro'...” (DC, §308). De modo que as coisas que sabemos e podemos dar razões para tal estão dentro do sistema de crenças e são passíveis de atribuição de valor de verdade, enquanto as coisas que "sabemos" do tipo que Moore diz saber se dará nas proposições com aparente forma de proposição empírica, mas que na verdade são normas que condicionam o jogo de linguagem, e estas não são passíveis de atribuição de valor de verdade por serem não-justificadas. Este posicionamento será mais bem expresso na discussão a seguir, e para darmos sequência a nossa reflexão, temos de colocar a questão: Em que se fundamentam as nossas crenças justificadas? 


\section{SEMINÁRIO DE PESQUISA EM CIÊNCIAS HUMANAS - SEPECH \\ Humanidades, Estado e desafios didático-científicos \\ Londrina, 27 a 29 de julho de 2016}

Pensemos em uma proposição de Moore, "Eu sei que esta é minha mão", qual seria o teste que, por exemplo, indicaremos para alguém que duvida que a mão que ele vê em sua frente seja dele? Poderíamos dizer "observe mais de perto", mas se ele duvida que a mão seja dele, não seria razoável pressupormos que este indivíduo também duvide

da sua visão? Parece que se formos entrar nesse abismo nunca pararemos e as justificações nunca terão fim. Pensemos também naquelas situações em que as crianças ficam perguntando o porquê das coisas e vamos tentando responder, isto é por isto, e isto é por aquilo outro, até que chega uma hora que esgotadas as razões, respondemos, "porque sim". Há uma necessidade clara de se parar a justificação, senão iríamos $a d$ infinitum e nada estaria justificado, diz Wittgenstein a este respeito: "Em algum ponto temos de passar da explicação para a mera descrição.” (DC, §189). Não demonstramos ainda a justificação de nossas crenças, mas já demonstramos a necessidade de em algum momento parar a justificação. Dizemos que sempre se pode testar uma proposição empírica, mas para fazer o teste não se tem que assumir algumas coisas como certas? Por exemplo, que nossos sentidos não nos enganam na observação dos instrumentos do laboratório, que estes existem etc. parece que há uma série de proposições que não são postas em duvida para se testar uma proposição empírica. E o mesmo não acontece quando calculamos? Não temos de assumir que aplicamos as regras corretamente, que nossas memórias não nos enganam, que os números misteriosamente não se alteram sozinhos etc.? Responde-nos Wittgenstein:

Não se pode experimentar se não houver coisas acerca das quais não se duvide. Mas isso não quer dizer que então tenha de se assumir de boa-fé certas pressuposições. Quando escrevo uma carta e a envio, suponho que ela chegará ao destino, isso eu espero. Quando faço experiências, eu não duvido da existência do aparelho que tenho diante dos meus olhos. Tenho um monte de dúvidas, mas não essa. Quando faço um cálculo, eu acredito, sem dúvida, que os números no papel não mudam espontaneamente, da mesma forma confio continuamente na minha memória, e a confiança é a incondicional. Aqui, a segurança é como aquela de que eu nunca estive na Lua. (DC, $\S 337$.$) .$

Estamos persuadidos que Wittgenstein está correto quando afirma que é uma condição lógica dos jogos de linguagem que algumas coisas sejam assumidas como certas, que haja segurança nelas, que um erro não seja possível quanto a determinadas coisas para que o jogo seja jogado, diz ele: "Porque, então, estou tão seguro de que isto é a minha mão? Todo o jogo de linguagem não se baseia nesse tipo de segurança? Ou: essa "segurança" (já) não é pressuposta no jogo de linguagem? Por exemplo, assim: quem não reconhecer com segurança objetos joga mal ou joga errado." (DC, §446). Estamos enfim em condições de dizer em que se fundam as nossas crenças justificadas, “(...)Contudo, o fim não é uma pressuposição não fundamentada, ele é, antes, um modo de agir não fundamentado." (DC, §110) e mais:

Mas a fundamentação, a justificação por meio de evidência, tem um fim; - e não encontramos o fim quando certas proposições nos são dadas imediatamente como verdadeiras, ou seja, ele não é um tipo de ver da 


\section{SEMINÁRIO DE PESQUISA EM CIÊNCIAS HUMANAS - SEPECH \\ Humanidades, Estado e desafios didático-científicos \\ Londrina, 27 a 29 de julho de 2016}

nossa parte, mas é, antes, o nosso agir que se encontra na base do jogo de linguagem. (DC, §204).

Para aqueles que ainda não se convenceram da necessidade de algo estar na base como firme, podemos dizer, "Quem não está certo de nenhum facto, também não pode estar certo do sentido do que diz.” (DC, §114.), estabelecido este ponto podemos dar

inicio a discussão do "agir não fundamentado". O que tem de interessante nas proposições de Moore como demonstra Wittgenstein, não é que ele as sabe, e todos nós sabemos, na verdade defendemos a ideia aqui de que Moore não as sabe de fato, faltariam razões para isso, mas as proposições de Moore elas fazem parte das proposições que são firmes para nós de tal forma que elas funcionam de ponto de referência para todo nosso julgar, ou seja, elas fazem parte das crenças não fundamentadas que fundam todo nosso sistema de crença, (por isso podemos dizer que todos pressupõem que as "saibamos", na verdade se defendermos a ideia que o saber pede razões, elas não teriam razões que justificariam nossa crença nelas, mas a segurança nas proposições de Moore é condição para podermos jogar os jogos de linguagem).

Cabe falar que o agir não fundamentado demonstra as crenças não fundamentadas que são a base fundadora do nosso sistema, grosso modo, eu sempre ajo de acordo com a existência de meus pés, não duvido deles em vez nenhuma, assim é firme para mim que meus pés existem e são meus. Essa leitura faz sentido na medida em que Wittgenstein também afirma "Na base da crença fundamentada está a crença não fundamentada." (DC, §253). Qual é então a grande dificuldade? "A dificuldade é reconhecer a não-fundamentação da nossa crença." (DC, §166). Aqui devemos entender que Wittgenstein fala das crenças que nós não podemos "saber", pois as crenças que são a base de nosso julgar não são passíveis de atribuição de valor de verdade, enquanto as crenças que estão dentro do sistema, por outro lado, podem ser "testadas" e assim decididas se são verdadeiras ou falsas. Pensemos, por exemplo, na matemática: concordamos que a matemática é um sistema, e que todas as proposições dentro dela são passíveis de decidibilidade, ou seja, atribuição de valor de verdade, mas as bases da matemática que são seus axiomas, não fazem parte do sistema como o resto derivado deles, de modo que eles não são fundamentados nesse sentido, uma vez que a pergunta para eles: isso é verdadeiro ou falso? É no nosso entender destituída de sentido. Mas podemos dizer que para calcular não duvidamos deles. Compreendemos os jogos de linguagem a partir de Wittgenstein também nos mesmos moldes que a descrição que fizemos da matemática, no sentido de que há uma base não justificada, que simplesmente é firme para nós, porque nos foi ensinado assim, que serve de referencial para todas as outras crenças justificadas dentro do sistema de crenças. Vejamos esta citação onde Wittgenstein fala que podemos transformar uma proposição empírica em norma de descrição:

É claro que nem todas as nossas declarações empíricas têm o mesmo status, visto que é possível estipular uma proposição desse tipo e convertê-la de proposição empírica numa norma de descrição. Pensemos nas investigações da química. Lavoisier faz experiências com substâncias no seu laboratório e então conclui que isto e aquilo ocorrem quando há combustão. Ele não diz que noutra ocasião talvez possa 


\section{SEMINÁRIO DE PESQUISA EM CIÊNCIAS HUMANAS - SEPECH \\ Humanidades, Estado e desafios didático-científicos \\ Londrina, 27 a 29 de julho de 2016}

acontecer algo diferente. Ele agarra-se a uma determinada imagem de mundo que ele, naturalmente, não inventou, mas aprendeu quando criança. Eu digo imagem de mundo e não hipótese, porque ela é a base auto-evidente da sua pesquisa e como tal também não é proferida. (DC, $\S 167$, Grifo nosso, exceto “status”.).

De modo que parece claro a nós que o caminho que trouxe ao desembocar da última citação pede que aprofundemos e expliquemos a seguir o papel de uma proposição aparentemente empírica como norma de descrição e mais o conceito de "imagem de mundo".

Precisamos explicar algo que pode ter ficado confuso no parágrafo anterior, esclareceremos esta confusão e ainda daremos conta do que dissemos que faríamos no final do parágrafo acima. Quando dissemos através de Wittgenstein que Moore não sabe as proposições que diz saber, estávamos dizendo quanto ao fato do saber dentro do jogo de linguagem, que pede razões, mas as proposições mooreanas elas fazem parte das proposições que todos assumem que "sabemos" que tornam possível o jogo dos jogos de linguagem. Elas não são justificadas, afinal elas são a base, e a base como já dissemos anteriormente é a crença não fundamentada, ou ainda, o agir não fundamentado. Portanto, essas proposições são aquelas que excluídas da dúvida servem “(...) como o eixo de rotação de um corpo em movimento giratório. Esse eixo não está fixo na medida em que está preso por algo, é o movimento ao seu redor que o determina como imóvel." (DC, §152) e assim "O ser humano não pode errar em certas circunstâncias." (DC, §155), afinal "Se o meu nome não é L.W., como posso ter confiança sobre o que deve ser entendido como 'verdadeiro' e 'falso'?” (DC, §515). Com efeito, podemos dizer então "A minha (nossa) vida funda-se no facto de (nos) me conformar (mos) com muita coisa." (DC, §344, parênteses nosso). De modo que estamos em condições de afirmar que as proposições que estão na base, que são nossas crenças não fundamentadas, demonstra aquilo que é firme na nossa imagem de mundo, e "(...) Ela (a imagem de mundo) é antes o pano de fundo herdado da tradição e sobre o qual diferencio entre verdadeiro e falso (...). E o seu papel é semelhante ao das regras de um jogo, e o jogo também pode ser aprendido puramente na prática, sem qualquer regra explícita." (DC, §94-95, parênteses nosso). Cabe dizer que há um movimento das proposições empíricas, ora elas funcionam como normas, ora como uma proposição empírica passível de teste, como fica claro quando Wittgenstein diz:

Poder-se-ia pensar que certas proposições com a forma de proposições empíricas seriam solidificadas e funcionariam como canais para as empíricas não solidificadas e ainda fluidas; e que essa relação se modificaria com o tempo à medida em que as proposições fluidas se tornassem solidificas $\mathrm{e}$ as firmes se tornassem fluidas. A mitologia pode pôr-se novamente em movimento, o leito do rio de pensamentos pode deslocar-se. Mas diferencio entre o movimento das águas do leito do rio e o deslocamento desse leito; embora não exista uma separação precisa entre ambos. Mas se alguém dissesse "Portanto, a lógica é também uma ciência empírica", estaria enganado. Mas é correto dizer que a mesma 


\section{SEMINÁRIO DE PESQUISA EM CIÊNCIAS HUMANAS - SEPECH \\ Humanidades, Estado e desafios didático-científicos \\ Londrina, 27 a 29 de julho de 2016}

proposição pode ser tratada ora como passível de teste pela experiência, ora como regra do teste. (DC, $\S \S \S 96-97-98)$.

Por fim, queremos dizer, primeiro, que a segurança que sentimos nas proposições normativas não é de modo algum uma segurança subjetiva, como já tínhamos adiantado no terceiro parágrafo desta seção. Temos nas proposições básicas a demonstração da nossa imagem de mundo que não é particular de cada indivíduo, mas é antes a somatória das coisas que nos foram ensinadas e foram se solidificando com o passar da vida e que

funcionam como regra para nossos jogos de linguagem, portanto a segurança nelas é objetiva; essas proposições como diz Wittgenstein, pegaram a via do esquecimento e não são mais postas em dúvida por nós, pode ser que algumas delas de fato nunca tenham sido postas em dúvida, a dificuldade realmente reside em aceitarmos a nãofundamentação destas proposições. Mas pretendemos com este artigo ter demonstrado que o papel delas é fundamental para a justificação do sistema de crenças, uma vez que sem crenças básicas não justificadas, não há um referencial para a atribuição de valor de verdade para as proposições empíricas que estão dentro do sistema. Mas como isso é possível? É possível justamente porque temos uma imagem de mundo compartilhada com outros seres humanos na qual as bases não são postas em dúvida, há uma intersubjetividade dessa imagem de mundo. Podemos dizer que a imagem de mundo, aquilo que herdamos da tradição porque ela se forma conforme foram nos ensinando, é a engrenagem central para a possibilidade de justificação das crenças dentro do sistema, uma vez que a demonstração mais clara dela é justamente as crenças firmes não justificadas.

Quando crianças, aprendemos factos, como, por exemplo, que cada pessoa tem um cérebro, e aceitamo-los com credulidade. Acredito que há uma ilha, a Austrália, que tem tal e tal forma etc., etc., acredito que tive bisavós, que as pessoas que se diziam meus pais eram meus pais, etc. Essa crença pode jamais ter sido proferida e o pensamento de que é assim jamais ter sido pensado. (DC, §159). O que se encontra nos livros didáticos, de geografia, por exemplo, tomo geralmente por verdade. Porquê? Digo: todos esses factos foram confirmados uma centena de vezes. Mas como sei isso? Qual é a minha prova a favor? Eu tenho uma imagem de mundo. Ela é verdadeira ou falsa? Acima de tudo, ela é o substrato de todas as minhas pesquisas e afirmações. As proposições que a descrevem não são todas sujeitas a teste da mesma forma. (DC, §162).

Por último, gostaríamos que ficasse expresso o nosso não aprofundamento do conceito de imagem de mundo e todas as possibilidades de relação com outros conceitos, por exemplo, formas de vida, das Investigações Filosóficas do próprio Wittgenstein, e que tal intento cabe a futuras pesquisas, tendo pretendido neste trabalho apenas demonstrar como toda a construção do argumento de Wittgenstein desemboca de alguma forma neste conceito e como ele seria a engrenagem central nos nossos sistemas de crenças. 


\title{
XI SEMINÁRIO DE PESQUISA EM CIÊNCIAS HUMANAS - SEPECH \\ Humanidades, Estado e desafios didático-científicos \\ Londrina, 27 a 29 de julho de 2016
}

\begin{abstract}
Mas pode-se perguntar: "Alguém pode ter razões concludentes para acreditar que a Terra existe há pouco tempo, digamos, desde o seu nascimento?" - Suponha-se que sempre lhe tenham dito isso, - ele teria uma boa razão para duvidar? Houve pessoas que acreditaram que podiam fazer chover; por que um rei não deveria ser educado com a crença de que o mundo começou com ele? E se agora Moore e esse rei se encontrassem e discutissem, Moore poderia realmente provar que a sua crença era a correta? Não digo que Moore não poderia converter o rei ao seu ponto de vista, mas esta seria uma conversão de um tipo especial: o rei seria levado a ver o mundo de outro modo. (...). (DC, $\S 92$, grifo nosso.)
\end{abstract}

\section{CONSIDERAÇÕES FINAIS}

Estamos persuadidos que todos os intentos colocados na introdução do trabalho foram atendidos de maneira satisfatória. Em resumo, temos com Wittgenstein no $D a$ Certeza uma demonstração de que nossas crenças justificadas se fundam em um agir não fundamentado, pensamento que parece fazer muito sentido caso se observe atentamente nossas vidas cotidianas e mesmo científica. Pensemos, por exemplo, na pergunta "há objetos físicos?" que devemos concordar é majoritariamente uma questão de cunho filosófico, tem de fato algum sentido de ser feita? Estamos seguros de que não, afinal sempre agimos de acordo com a existência de objetos físicos: sentamos na poltrona, abrimos o livro, lemos tal livro, tomamos a xícara de café, e ainda temos a incondicional segurança de que aquilo que está escrito no livro não muda aleatoriamente, por qual razão então deveríamos colocar em dúvida a existência de objetos físicos? A crença na existência de objetos físicos é uma crença básica, e ela não é passível de atribuição de valor de verdade. De modo que demonstramos no nosso trabalho que as crenças básicas são condições e normas dos nossos jogos de linguagem e elas não fazem parte daquele saber que pede razões, ou, portanto, elas não fazem parte do nosso conhecimento justificado, elas fazem parte, sim, daquilo que simplesmente é firme para nós em nossa imagem de mundo.

O caminho aqui trilhado é apenas a porta de entrada para uma pesquisa maior e mais aprofundada, pensamos em algum momento futuro relacionar se possível a obra de Thomas S. Kuhn, a saber, A Estrutura das Revoluções Cientificas, com o pensamento de Wittgenstein, e ainda em um âmbito um pouco mais ousado relacionar o pensamento de Wittgenstein no Da Certeza com o pensamento de Willard Van Orman Quine, também claro, se possível. O que de fato até o presente momento já ocorreu, foi que o pensamento de Wittgenstein nos remeteu a uma passagem específica de um célebre artigo de Quine, a saber, Dois dogmas do empirismo, e a passagem é a seguinte: "A cada homem é dada uma herança científica, acrescida de um bombardeio contínuo de estimulação sensorial; e as considerações que o guiam na elaboração de sua herança científica para ajustar suas contínuas incitações sensórias são, quando racionais, pragmáticas." (QUINE, 2011, pg. 71). De modo que temos duas considerações finais: devemos perguntar ao sistema se ele funciona ao que se propõe ou não, não se ele é verdadeiro ou falso; e dois, mudamos a perspectiva de Descartes, não mais um fundamento sólido para construir o sistema, mas o sistema segurar o não fundamentado de alguma forma, em alguma medida o Wittgenstein corrobora o que dizemos: 


\section{SEMINÁRIO DE PESQUISA EM CIÊNCIAS HUMANAS - SEPECH \\ Humanidades, Estado e desafios didático-científicos \\ Londrina, 27 a 29 de julho de 2016}

"Cheguei à base das minhas convicções. E dessa fundação quase se poderia dizer que ela é sustentada por toda a casa.” (DC, §248).

\section{REFERÊNCIAS BIBLIOGRÁFICAS}

DESCARTES, René. Meditações. 4a..Ed. São Paulo: Nova Cultural, 1987-1988.

HUME, David. Investigação acerca do entendimento humano. $5^{\text {a }}$. Ed. São Paulo: Nova Cultural, 1992.

KUHN, Thomas S. A estrutura das evoluções cientificas. São Paulo: Editora Perspectiva S.A. 2000.

MOORE, George Edward. Escritos filosóficos. São Paulo: Nova Cultural, 1989.

PICH, Roberto Hofmeister. Wittgenstein Sobre Certeza, Regras e Normas, Dossiê Wittgenstein, Dissertatio - Volume Suplementar 01 | UFPel [2015].

QUINE, Willard Van Orman. De um ponto de vista lógico: nove ensaios lógicofilosóficos. São Paulo: Editora Unesp, 2011.

SOARES, Jean D. Das aproximações de Kuhn com Wittgenstein. Griot - Revista de Filosofia, Amargosa, Bahia - Brasil, v.3, n.1, junho/2011.

WITTGENSTEIN, Ludwig. Da certeza. Lisboa/ Portugal: Edições 70 Ltda. 2012. . Investigações filosóficas. São Paulo: Nova Cultural, 1989. 